\title{
The Rabbit Shunt Model of Subarachnoid Haemorrhage
}

\author{
Serge Marbacher • Edin Nevzati • Davide Croci • \\ Salome Erhardt • Carl Muroi • Stephan M. Jakob • \\ Javier Fandino
}

Received: 29 May 2014 / Revised: 15 August 2014 / Accepted: 1 September 2014 /Published online: 19 October 2014

(C) Springer Science+Business Media New York 2014

\begin{abstract}
Aneurysmal subarachnoid haemorrhage (SAH) is a disease with devastating complications that leads to stroke, permanent neurological deficits and death. Clinical and experimental work has demonstrated the importance of the contribution of delayed cerebral vasospasm (DCVS) indepen-dent early events to mortality, morbidity and functional out-come after SAH. In order to elucidate processes involved in early brain injury (EBI), animal models that reflect acute events of aneurysmal bleeding, such as increase in intracranial pressure (ICP) and decrease in cerebral perfusion pressure, are needed. In the presented arterial shunt model, bleeding is initially driven by the pressure gradient between mean arterial blood pressure and ICP. SAH dynamics (flow rate, volume and duration) depend on physiological reactions and local anatomical intrathecal (cistern) conditions. During SAH, ICP reaches a plateau close to diastolic arterial blood pressure and the blood flow stops. Historical background, anaesthesia, perioperative care and monitoring, SAH induction, technical considerations and advantages and limitations of the rabbit blood shunt SAH model are discussed in detail. Awareness of technical details, physiological characteristics and appropriate monitoring methods guarantees successful implementation of the rabbit blood shunt model and allows the study of both EBI and DCVS after SAH.
\end{abstract}

S. Marbacher $\cdot$ E. Nevzati $\cdot$ D. Croci $\cdot$ S. Erhardt $\cdot$ C. Muroi $\cdot$

S. M. Jakob · J. Fandino

Cerebrovascular Research Laboratory of the Department of Intensive

Care Medicine, University Hospital and University of Bern, Bern, Switzerland

S. Marbacher $(\varangle) \cdot$ E. Nevzati $\cdot$ D. Croci $\cdot$ S. Erhardt $\cdot$ C. Muroi $\cdot$ J. Fandino

Department of Neurosurgery, Kantonsspital Aarau, 5001 Aarau,

Switzerland

e-mail: serge.marbacher@ksa.ch
Keywords Subarachnoid haemorrhage · Animal models . Rabbit $\cdot$ Arterial blood shunt $\cdot$ Early brain injury $\cdot$ Delayed cerebral vasospasm $\cdot$ Microsurgery

\section{Introduction}

Aneurysmal subarachnoid haemorrhage (SAH) is a disease with devastating complications that leads to stroke, permanent neurological deficits and death. Despite major improvements in surgical techniques, diagnosis and interventional treatment, average case fatality rates for SAH remain between 40 and $50 \%$ [1], and only $60 \%$ [2] of surviving patients will return to work. The disease mainly affects relatively young patients, causing significant socioeconomic impact [3].

Following the first description of delayed cerebral vasospasm (DCVS) after aneurysm rupture by Ecker and Riemenschneider [4] in 1951, DCVS was believed to be the main cause of ischemia, infarction and poor patient outcome. In 1997, endothelin A receptor (ET-1A) antagonists were found to prevent DCVS after SAH in a double cisterna magna autologous blood injection model in rats [5]. One year, later these promising results were confirmed in a singlehaemorrhage cisterna magna injection rabbit model [6]. After publication of phase, the $2 \mathrm{a}$ [7] and $2 \mathrm{~b}$ [8] multi-centre study results, the phase 3 [9] trial demonstrated no statistically significant effect on DCVS-related morbidity, mortality or functional outcome.

Clinical and experimental work has long demonstrated the importance of DCVS-independent early events after SAH [10-12]. However, the disappointing results of the phase-3 ET-1A antagonist study have led to increased interest in the phenomenon of early brain injury (EBI) after SAH. The change of focus was interpreted as a paradigm shift from DCVS to EBI [13-15]. EBI is an umbrella term that covers complex pathophysiological mechanisms occurring within the 
first few days after aneurysm rupture. The triggers and biological mechanisms that cause EBI are just being discovered and are not yet fully understood. Increase in intracranial pressure (ICP) during aneurysm rupture and the associated sequels are believed to be crucial to the pathophysiologies that develop in EBI following acute SAH.

According to the previous paradigm stating that DCVS is the main contributor to poor clinical outcomes after SAH, most animal models have traditionally been designed to produce consistently high degrees of DCVS but not to reflect acute events of SAH. Until 2007, rat and rabbit animal models were the most often used for the study of DCVS [16]. In the rabbit, virtually all studies (98\%) were performed using the cisterna magna blood injection technique ( $84 \%$ single and $14 \%$ multiple injections). In order to elucidate processes involved in EBI, animal models that reflect acute events of aneurysmal bleeding (such as increase in intracranial pressure $[\mathrm{ICP}]$ and decrease in cerebral perfusion pressure [CPP]) are needed [13]. To overcome limitations of current experimental SAH techniques, we developed an examiner-independent controllable SAH rabbit model that simulates early events of aneurysm rupture and triggers moderate to severe degrees of DCVS. The dynamics of the "spontaneous" bleeding into the subarachnoid space depend solely on the rabbit's anatomical and physiological conditions.

\section{The Rabbit Model of Subarachnoid Haemorrhage}

Historical Background, Evolution and Modification Over the Years

In the early 1980 s, the rabbit emerged as a new species for DCVS research. Initially, Edvinsson et al. [17] injected autologous blood into the prechiasmatic and basal cistern. In the ensuing years, other researchers simplified the route through either open or transcutaneous injection into the cisterna magna [18-21]. Over time, the single cisterna magna injection became the gold standard for SAH induction in rabbits [16]. The multiple blood injection model was considered controversial among experts, leading to the deferral of its use. In 1989, Spallone and Pastore [22] evaluated the double-haemorrhage approach and found that multiple injections did not enhance DCVS, but are associated with an increased rate of mortality (>50\%). In 2007, Zhou was the first to present that the modified double-haemorrhage model (percutaneous injection and longer time interval between injections) produced significantly more severe DCVS and a very low rate of mortality $(6 \%)$ in a direct comparison of single and double blood injection [23].

Logothetis et al. made the first attempt to establish the rabbit model for the examination of both acute and late events after SAH [24]. They punctured the posterior branch of the middle cerebral artery and superior sagittal sinus. Egemen et al. performed a basilar artery puncture from a transclival approach [25]. Although both models do simulate acute SAH through arterial bleeding into the subarachnoid space in a closed cranium (if the skull is adequately closed), the models have not been validated for the study of EBI and have never been replicated since their original publication. In addition, puncture models have been criticised for their extensive intracranial manipulation.

The concept of simulating arterial subarachnoid bleeding within a closed cranium by shunting an artery into the subarachnoid space is not new and has been described in dogs [26, 27], cats [28], rabbits [29] and rats [30] (Fig. 1). Offerhaus and van Gool [29] were the first to use an artery-cisternal shunt (carotid artery-chiasmatic cistern) to induce acute experimental SAH and to study electrocardiographic changes and catecholamine release. Steiner et al. [26] produced an intrathecal haemorrhage by shunt from the femoral artery to

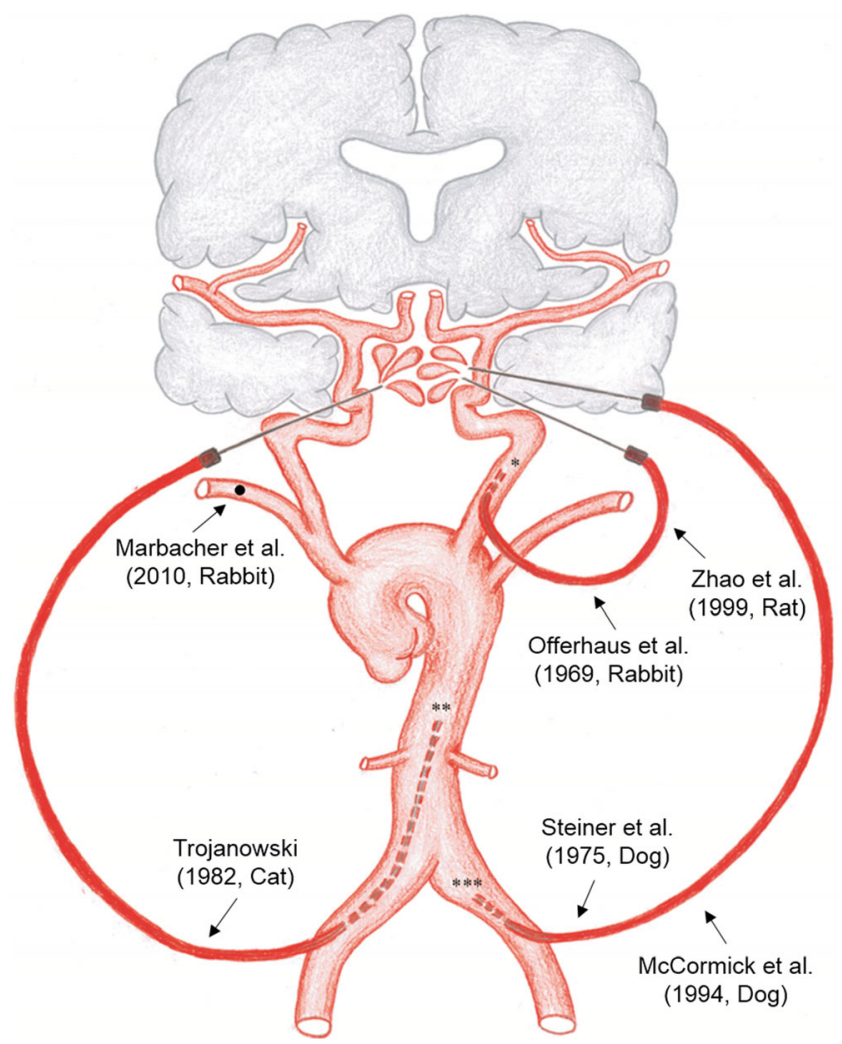

Fig. 1 Various models of shunt-induced SAH. This drawing demonstrates various shunt techniques in different species. In rats and rabbits, a polyethylene tube in the prechiasmatic cistern was connected to the left common carotid artery $\left(^{*}\right)$. In cats, a catheter placed in the abdominal aorta $(* *)$ was connected with a needle in the prechiasmatic cistern. In dogs, a cannula was placed at various cranial sites and connected to the left femoral artery (***). In the presented blood shunt SAH rabbit model, the left subclavian artery $(\bullet)$ is cannulated and connected via three-way stopcock to the paediatric spinal tap needle placed in the cisterna magna. (Reprinted with permission of Br J Neurosurgery, Standard intracranial in vivo animal models of delayed cerebral vasospasm by Marbacher et al. 2010. Copyright 2010 by Informa Healthcare) 
one of four intracranial sites (cerebral parenchyma, cisterna chiasmatica, lateral ventricle and cisterna magna) to examine the role of multiple bleeding sites in relation to localisation, ICP increase and vital functions. McCormick et al. [27] adapted the femoral-cisternal shunt described by Steiner et al. by adding a pressurised reservoir that allowed only unidirectional flow and examined the mechanisms of SAH arrest. Zhao et al. simulated the acute period of SAH using a rat common carotid artery-prechiasmal extracorporeal shunt to study the phenomenon of sudden death. Trojanowski [28] used abdominal aorta-perichiasmatic shunt model in cats to study dynamics of SAH regarding flow, volume and time of blood extravasation into the subarachnoid space.

The models were introduced to overcome shortcomings in blood injection (arbitrary ICP increase) and vessel puncture models (missing control of severity of bleeding) while studying acute events during SAH. The refined shunt-induced models induce controllable bleeding in terms of ICP increase and amount of blood being distributed in the subarachnoid space. However, the shunt model of SAH has only been recently evaluated in rabbits for the study of DCVS [31] or EBI [32].

\section{The Rabbit Subarachnoid Haemorrhage Shunt Model}

\section{Description of Animals Used}

New Zealand white rabbits are timid, nonaggressive, easy to handle and relatively inexpensive to maintain. They are kept in rooms with controlled temperature $\left(20 \pm 2{ }^{\circ} \mathrm{C}\right), 50 \%$ humidity, under a 12-hour/12-hour day-night cycle. Food pellets (they eat throughout the day) and tap water (up to $100 \mathrm{ml} / \mathrm{kg}$ / day) are provided without restriction. Unfortunately, isosexual group-housing of male animals inevitably leads to severe fighting, reflecting the biological intolerance of male rabbits. As rabbits must be housed in groups (two to four per cage, with the exception of sick animals and those recovering from anaesthetic) due to animal welfare regulations, female animals are preferred. Using females, however, increases the risk of estrogens attenuating SAH-induced apoptosis [33].

With the exception of haematocrit values, whole blood haemoglobin concentration, percentage of granulocyte and serum potassium concentration, there are no statistically significant differences in haematological and biochemical normal values between male and female animals [29]. Young (2month-old, growing) rabbits demonstrate altered haematological and biochemical characteristics as compared to adult (2year-old) rabbits [34]. One interesting finding is that the time course of DCVS depends on the rabbits' age. In young rabbits, arterial calibre returned almost to baseline 7 days after SAH, whereas older rabbits (20 to 40 months) showed continuous vasospasm with near maximal constriction 1 week after initial iatrogenic bleeding [35]. The physiological parameters are summarised in Table 1.

Details of Anaesthesia and Analgesia, Perioperative Care and Monitoring

General anaesthesia in the rabbit is induced through intramuscular injection of ketamine ( $30 \mathrm{mg} / \mathrm{kg}$; Ketalar, $50 \mathrm{mg} / \mathrm{ml}$ ) and xylazine (6 mg/kg; Xylapan $20 \mathrm{mg} / \mathrm{ml}$ ). Depth of anaesthesia is controlled by testing the rabbit's response to noxious stimulation (e.g. toe-pinch), decrease of palpebral and corneal reflexes and extent of muscle relaxation. In case of positive response to noxious stimulation, the depth of anaesthesia is adapted by ketamine bolus ( $6 \mathrm{mg} / \mathrm{kg}$ ) i.v. and xylazine bolus $(0.05 \mathrm{mg} / \mathrm{kg})$ i.v. and/or an additional analgesia bolus with fentanyl $(1 \mathrm{mcg} / \mathrm{kg})$ i.v. Due to the half-life of ketamine and xylazine, the recovery time of control (sham-operated) animals is quite short (approximately $1 \mathrm{~h}$ ). Delayed recovery time (approximately $3 \mathrm{~h}$ ) can be expected in animals after blood shunt induction. Transdermal fentanyl patches releasing $12.5 \mu \mathrm{g} / \mathrm{h}$ are applied to the shaved neck region of the animals, providing effective analgesia for the following $72 \mathrm{~h}$. A veterinary anaesthesiologist monitors the animals during surgery and throughout anaesthetic recovery. The animals are not returned to the company of other animals until they regain sufficient consciousness.

The direct influence of different anaesthetics on neuronal cells (neuroprotective and neurotoxic) and potential influence on pathophysiology (changes in cerebral metabolic rate, ICP, CPP, systemic blood pressure) and outcome after experimental SAH in rabbits remains - to the best of our knowledgeunexplored. In rats, the striking impact of anaesthesia on pathophysiology following $\mathrm{SAH}$ has been demonstrated [36]. It remains unknown whether, and to what extent, the use of ketamine (an antagonist of NMDA receptors)/ xylazine (agonist at the $\alpha 2$ class of adrenergic receptor) anaesthesia compromise neuronal cell death after SAH in the blood shunt model presented. Nevertheless, the impact of the acute SAH on apoptosis can be highlighted by the differences observed between SAH animals and sham controls [32]. Furthermore, one also needs to keep in mind that anaesthesia can change physiological blood gas status [37]. Different use of combinations of sedatives and opioids significantly influences decrease in respiratory rate and degree of hypoxemia and hypercapnia evidenced by arterial blood gas analysis [38]. This is of particular importance as $\mathrm{pCO}_{2}$ influences cerebral artery diameter [39, 40]. While in mechanically ventilated rabbits, blood gas values can be kept in a physiologic range and mortality due to respiratory arrest during acute SAH is reduced, it remains a matter of debate whether experimental $\mathrm{SAH}$ in spontaneously breathing animals (or awake animals 
Table 1 Selected physiologic parameters in New Zealand white rabbits

${ }^{a}$ Haematological parameters measured in the blood of adult female New Zealand rabbits [66]

${ }^{\mathrm{b}}$ Blood gas parameters in adult $(\sim 3 \mathrm{~kg})$ female New Zealand rabbits without anaesthesia. Please see text for explanation of abbreviations [37]

\begin{tabular}{|c|c|c|}
\hline Physiological parameters & Values & \\
\hline Body weight & $2-6 \mathrm{~kg}$ & \\
\hline Body temperature & $38.5-39.5^{\circ} \mathrm{C}$ & \\
\hline Heart rate & $120-300 /$ per min & \\
\hline Respiratory rate & $30-120 / \mathrm{min}$ & \\
\hline Total ventilation & $0.8 \mathrm{l} / \mathrm{min}$ & \\
\hline Water consumption & $120 \mathrm{ml} / \mathrm{kg} /$ day & \\
\hline Food consumption & $100-300 \mathrm{~g} /$ day & \\
\hline Mean life span & 8 years & \\
\hline Sexual maturity age & 4-6 months & \\
\hline Intracranial pressure & $5-10 \mathrm{mmHg}$ & \\
\hline Brain weight & $14 \mathrm{~g}$ & \\
\hline Basilar artery diameter & $600-800 \mu \mathrm{m}$ & \\
\hline Haematological parameters ${ }^{\mathrm{a}}$ & Values (mean \pm SEM) & Range \\
\hline HTC (\%) & $42.2 \pm 1.1$ & $33.1-47.7$ \\
\hline Haemoglobin $(\mathrm{g} / \mathrm{dl})$ & $14.8 \pm 5.4$ & $10.8-17.5$ \\
\hline White blood count $\left(\times 10^{6} / \mathrm{mm}^{3}\right)$ & $10.4 \pm 1.1$ & $5.8-20.1$ \\
\hline Granulocytes $\left(\times 10^{6} / \mathrm{mm}^{3}\right)$ & $6.6 \pm 0.9$ & $1.7-14.7$ \\
\hline Total protein $(\mathrm{g} / \mathrm{l})$ & $62.5 \pm 2.2$ & $49-79$ \\
\hline Glucose (mmol/l) & $6.6 \pm 0.3$ & $4.9-8.3$ \\
\hline $\mathrm{Ca}^{2+}(\mathrm{mmol} / \mathrm{l})$ & $3.0 \pm 0.1$ & $2.5-3.7$ \\
\hline $\mathrm{Na}^{+}(\mathrm{mmol} / \mathrm{l})$ & $141.6 \pm 0.5$ & $139.3-145.7$ \\
\hline $\mathrm{K}^{+}(\mathrm{mmol} / \mathrm{l})$ & $4.1 \pm 0.1$ & $3.0-4.7$ \\
\hline Blood gas parameters ${ }^{\mathrm{b}}$ & Values (mean \pm SEM) & \\
\hline $\mathrm{pH}$ & $7.44 \pm 0.04$ & \\
\hline $\mathrm{pCO}_{2}(\mathrm{mmHg})$ & $32.4 \pm 1$ & \\
\hline $\mathrm{pO}_{2}(\mathrm{mmHg})$ & $88 \pm 3$ & \\
\hline $\mathrm{HCO}_{3}^{-}(\mathrm{mmol} / \mathrm{l})$ & $22.5 \pm 1.2$ & \\
\hline $\mathrm{TCO}_{2}(\mathrm{mmol} / \mathrm{l})$ & $23.5 \pm 1.2$ & \\
\hline $\mathrm{BEb}(\mathrm{mmol} / \mathrm{l})$ & $-0.2 \pm 1.4$ & \\
\hline $\mathrm{SO}_{2} \mathrm{c}$ & $96.9 \pm 0.9 \%$ & \\
\hline
\end{tabular}

[41]) mimics the human situation of aneurysm rupture more closely.

In our experimental setting, the following physiological parameters are routinely monitored during the experiments: heart rate, electrocardiogram, core temperature, arterial blood pressure, peripheral oxygen saturation, respiratory rate (based on end expiratory carbon dioxide curve), core temperature, cerebral blood flow in the right and left hemisphere and intracranial pressure. The following laboratory parameters are assessed: $\mathrm{pH}$, partial pressure of carbon dioxide $\left(\mathrm{pCO}_{2}\right)$, partial pressure of oxygen $\left(\mathrm{pO}_{2}\right)$, sodium $\left(\mathrm{Na}^{+}\right)$, potassium $\left(\mathrm{K}^{+}\right)$, glucose $(\mathrm{Glu})$, lactate ( $\left.\mathrm{Lac}\right)$, haematocrit level, haemoglobin $(\mathrm{Hb})$, actual bicarbonate $\left(\mathrm{HCO}_{3}{ }^{-}\right)$, total carbon dioxide content $\left(\mathrm{TCO}_{2}\right)$, bases excess $(\mathrm{BEb})$ and calculated oxygen saturation $\left(\mathrm{SO}_{2} \mathrm{c}\right)$.

After SAH, we keep the animals under close observation for at least $3 \mathrm{~h}$. Afterwards, the neurological status is graded at $6,12,24,48$ and $72 \mathrm{~h}$ post-SAH according to the four-point grading system reported by Endo et al. [20]: grade 1, no neurological deficit; grade 2, minimal or suspected neurological deficit; grade 3, mild neurological deficit without abnormal movement; and grade 4, severe neurological deficit with abnormal movement. Food intake is recorded as none, reduced or normal. During the first $3 \mathrm{~h}$, sham-operated controls recover significantly faster than rabbits which have undergone blood shunt-induced SAH. SAH rabbits show progressive aggravation of neurological deficits on days one to three [31]. Drowsiness and reduced movements are noted in most animals after SAH. Focal neurological deficits such as severe limb weakness or hemiparesis are rare [31, 32]. SAH animal mortality can rise to $18-25 \%$ due to respiratory arrest and severe bradycardia during peak ICP [31, 32].

\section{Detailed Description of SAH Induction}

Technical aspects and a detailed standard operating procedure of the blood shunt SAH model in the rabbit is given elsewhere [42]. In brief, the most important steps are the following: (1) 
firstly, (supine position) the left subclavian artery is cannulated. (2) In the second step, digital subtraction angiography of the basilar artery is performed by retrograde injection of contrast agent. (3) Then, the animal is repositioned (prone position), neuromonitoring probes are installed (according to outer skull landmarks [43]), and a spinal access needle is inserted into the cisterna magna. (4) In the final step, the spinal access needle and the subclavian artery are connected to a shunt. The SAH can be initiated by opening the shunt, allowing the blood to stream into the subarachnoid space under arterial pressure.

Sham-operated animals undergo neuromonitoring placement and puncture of the cisterna magna. A saline control group could theoretically be performed using a pressurised reservoir similar to that previously used in dogs $(60 \mathrm{ml}$, under mean arterial blood pressure [MABP] $+/-5 \mathrm{mmHg}$ ) [27]. The volume of applied blood can be measured with a flow probe interposed in the shunt between the subclavian artery and the cisterna magna (Fig. 2) [31]. During SAH, ICP reaches a plateau close to diastolic arterial blood pressure, and then the flow in the shunt stops and allows the blood to coagulate. At that time, cerebrospinal fluid is completely displaced from the cisterna magna and effective clot formation occurs. The small amount (a few millilitre) of arterial blood lost for SAH induction does not cause hypovolemia and is not replaced nor is additional fluid provided until complete recovery.

In order to prevent "re-bleeding" we close the shunt when a plateau phase (ICP = diastolic blood pressure) is maintained for more than $10 \mathrm{~s}$ or ICP decreases spontaneously. Apart from this "spontaneous" stop of bleeding through coagulation, the shunt can also be closed at any point. This "controlled" SAH allows simulation of various degrees of bleeding by means of ICP increase or extravasated subarachnoid blood volume (provided that the shunt flow is measured).

After SAH induction, the neuromonitoring (ICP and cerebral blood flow $[\mathrm{CBF}]$ fine-needle probes) are removed and the burr holes sealed with bone wax. The subclavian artery catheter is carefully removed and ligated. Wounds are irrigated thoroughly with neomycin sulphate and sutured. For follow-up angiography, the animals undergo the same anaesthesia protocol as described above. The right subclavian artery is cannulated and digital subtraction angiography (DSA) is performed by retrograde intra-arterial bolus injection of nonionic iopamidol $(0.6 \mathrm{ml} / \mathrm{kg}$, for 1 to $2 \mathrm{~s})$ through the cannulated artery (Fig. 3). The cannula needs to be flushed with saline immediately after bolus contrast agent injection in order to prevent occlusion of the latter. In most cases, single baseline and follow-up angiography is needed for evaluation of DCVS over time, and hence, the most pragmatic way is to sacrifice the left and right subclavian artery for each angiography. However, if multiple baseline or follow-up angiographies are required, we suggest to consider selective angiography through the femoral artery and microcatheter placement in the brachiocephalic artery.

\section{Gross Examination of Brain and Pathophysiology}

The anatomy, adhesions in the subarachnoid space and cerebroventricular system in rabbits are largely different from that of humans [44]. During acute blood shunt-induced SAH



Fig. 2 Experimental setting. a Entry point for the percutaneous placement of the paediatric spinal tap needle into the cisterna (small dashed circle) and area of midline incision over the skull where the neuromonitoring is placed according to outer skull landmarks (large dashed circle). b The cannulated subclavian artery (*) is connected via three-way stopcock and pressure tube with the spinal tap needle placed in the cisterna magna $(* *)$. A flow probe $(1.5 \mathrm{~mm}$ diameter, $2.4 \mathrm{MHz}$ ultrasound flowprobe, Transonic Systems Inc., Ithaca, NY, USA) mounted on the pressure tube (inlet, an interposed rabbit aortic graft is needed to get accurate readings of flow) facilitates measurement of blood volume streaming under arterial pressure into the closed cranium 




Fig. 3 Digital subtraction angiography. Digital subtraction angiography of the basilar artery (black arrows) is performed by retrograde intraarterial bolus injection of nonionic Iopamidol $(0.6 \mathrm{ml} / \mathrm{kg}$, for 1 to $2 \mathrm{~s})$ through the left (baseline) and right (follow-up) subclavian artery. An external sizing device $\left(^{*}\right)$ is used as reference marker to minimise bias in image post-processing and measurement of the basilar artery diameter

there is no significant pressure gradient between the infratentorial and supratentorial compartment and free cerebrospinal fluid communication results in equal subarachnoid blood distribution at the ventral and dorsal surface of the brain and in supra- and infratentorial cisterns (chiasmatic and prechiasmatic cistern, basal cistern, prepontine and interpeduncular cisterns, and cistern magna) [31, 45, 32]. Unpublished data of recent experimental studies suggest that there is no correlation between increase in ICP and amount of blood distributed in the subarachnoid space.

Under general anaesthesia, intracardiac perfusion-fixation is carried out at room temperature with $400 \mathrm{ml}$ of $0.1 \mathrm{M}$ phosphate-buffered solution (PBS) followed by $400 \mathrm{ml}$ fixative (4\% paraformaldehyde in $0.1 \mathrm{M}$ PBS, $\mathrm{pH} 7.3$ ) under a perfusion pressure of 0.1 bar. The brains are carefully removed from the skull and the basal and hemispheric surfaces are photographed. The amount of SAH is quantified according to a slightly modified grading system previously published by Sugawara et al. [46]: 0, no blood; 1, minimal blood; 2, moderate blood clot (basal arteries visible); and 3, massive blood clot (visual obliteration of basal arteries). This bleeding scale is applied to the (1) chiasmatic and prechiasmatic cistern, (2) basal cistern, (3) prepontine and interpeduncular cistern, and (4) cistern magna. The summed score of all four cistern (range $0-12$ ) determine the final grade of mild (0-4), moderate (5-8) or severe (9-12) grade of SAH. One day after shuntinduced SAH more than $80 \%$ of the animals demonstrate a severe SAH sum score of 10 to 12 .

Despite the fact that blood streams under arterial pressure into the subarachnoid space intracerebral haematomas at the level of the brainstem do not occur. Intraventricular haemorrhage in the lateral and fourth ventricle is a rare finding. When precautions of meticulous and tight sealing of the burr holes as well as aseptic techniques in combination of antibiotic wound irrigation are followed, then it is highly unlikely that signs of cerebrospinal fluid leakage or wound infections will occur [42].

Opening the shunt allows arterial blood to stream under arterial pressure into the subarachnoid space. The bleeding pulsates, with systolic pressure peaks causing disruption of the delicate connective tissue strands of the arachnoid trabeculae and mechanical stress to cerebral artery walls. Brisk increases in ICP and decreases of CPP to almost zero results in global ischemia.

Within 2 to $3 \mathrm{~min}$ after shunt-induced SAH, ICP rise to peak values close to diastolic arterial blood pressure values. Within 5 to $10 \mathrm{~min}$, ICP then returns to a steady state (significantly higher than baseline values). During the first $3 \mathrm{~min}$ of acute $\mathrm{SAH}, \mathrm{CPP}$ drops significantly and $\mathrm{CBF}$ decreases equally in both hemispheres to approximately $20-30 \%$ of baseline values [32]. Augmentation of mean arterial blood pressure is frequently observed during the peak phase of SAH (Cushing reflex). As a result of the Cushing reflex, CPP recovers early after SAH induction. The heart rate regularly decreases after an initial increase at the time of SAH initiation.

These severe pathophysiological disturbances and their subsequent consequences cause early microclot formation, significant damage to the hippocampus, basal cortex and cerebral vasculature $24 \mathrm{~h}$ after shunt-induced SAH and triggers marked basilar artery vasoconstriction $72 \mathrm{~h}$ after initial bleeding [45, 32, 31]. Pathophysiological events caused by shunt-induced SAH are summarised in Table 2 and Fig. 4.

\section{Technical Considerations}

All surgical procedures are performed under sterile conditions. The most critical considerations and surgical steps required to ensure consistency and accuracy of the rabbit shunt SAH model are as follows: (1) age of the rabbit should not exceed 3-4 months in order to avoid increased mortality and prolonged DCVS [35], (2) secure ligatures of the subclavian artery are needed to prevent twisting or slippage of the catheter during careful repositioning from prone to supine position [42], (3) tight sealing of the burr holes (ICP and CBF monitoring probes) is essential to maintain a closed cranium condition [42], (4) calibration of the angiogram (using an external reference marker during DSA) must be carried out to ensure minimal bias in image post-processing [47], and (5) percutaneous puncture of the cisterna magna should be performed carefully and slowly using the external occipital protuberance (located through direct palpation) as a landmark (Fig. 5). Step-by-step procedural instructions, necessary equipment and technical nuances to perform the rabbit blood shunt SAH model with minimal mortality and morbidity are given elsewhere [42]. 
Table 2 Evolution of hemodynamic parameters and outcome data in New Zealand white rabbits at baseline, during and after shunt-induced subarachnoid haemorrhage

\begin{tabular}{ll}
\hline Parameters & Values \\
\hline Baseline & \\
MABP (mmHg) & $71 \pm 2$ \\
ICP (mmHg) & $7 \pm 1$ \\
CPP (mmHg) & $63 \pm 2$ \\
CBF (\%) & 100 \\
Peak & \\
MABP (mmHg) & $81 \pm 5$ \\
ICP (mmHg) & $54 \pm 5$ \\
CPP (mmHg) & $23 \pm 3$ \\
CBF (\%) & $34 \pm 4$ \\
Steady state & \\
MABP (mmHg) & $71 \pm 2$ \\
ICP (mmHg) & $20 \pm 1$ \\
CPP (mmHg) & $51 \pm 2$ \\
CBF (\%) & $78 \pm 6$ \\
DCVS & $\sim 30-50 \%$ of baseline (on day 3 after SAH) \\
Mortality rate & $\sim 15-25 \%$ (respiratory arrest/bradycardia) \\
Neurological deficits & $>90 \%$ grade 3 (on day 3 after SAH) \\
SAH sum score & $>80 \%$ score 10 to 12 (on day 1 after SAH) \\
\hline
\end{tabular}

${ }^{a}$ Please note that due to the Cushing reflex MABP reaches its peak later in time than maximal CPP depletion (see text)

${ }^{b}$ The time course of DCVS after shunt-induced SAH has not yet been established

${ }^{\mathrm{c}}$ Neurological status graded according to a four-point grading system (see text)

${ }^{\mathrm{d}} \mathrm{SAH}$ quantification according to a 12-point grading system (see text)

Discussion of Advantages and Limitations in Comparison with Other Models and Techniques

There are two principle methods to simulate bleeding in the subarachnoid space close to the large cerebral vessels. Either the blood is added from outside (via blood injection or craniotomy and blood clot placement) or an intracranial artery is injured (vessel puncture or rupture). Craniotomy and blood clot placement is technically challenging and results in potential mechanical irritation of the intracranial arteries and periarterial environment (the tamponading effect of the cistern during bleeding no longer exists, subdural and subarachnoid spaces are connected to each other). Injection of blood (as far as it is performed stereotactically and percutaneous) is a minimally invasive, simple and fast procedure, but the choice of injection dynamics (pressure and time) as well as volume are often arbitrary [16]. Neither of the two techniques where blood is added from the exterior closely reproduces pathophysiological sequels of aneurysm rupture.
Endoluminal puncture is very suitable to induce SAH as it closely mimics aneurysm rupture (arterial bleeding of pulsatile character within a closed cranium) [48, 49]. In contrast to all other intracranial artery injury models, the endovascular puncture model avoids any extensive intracranial manipulation associated with vessel puncture and vessel rupture through skull openings or implant device placement $[50,51,25,24,41,52,53]$. Nevertheless, no vessel injury model allows exact control of bleeding volume, time course or severity of ICP increase.

In the arterial shunt model, bleeding is initially driven by the pressure gradient between mean arterial blood pressure and ICP. Further SAH dynamics (flow rate, volume and duration) depend on physiological reactions and local anatomical intrathecal (cistern) conditions [27, 26]. Important physiological reactions such as the pulsatile character of the bleeding (pressure peaks), the Cushing phenomenon, ECG and EEG changes and development of mechanical resistance to repeated bleeding are documented using the arterial shunt model [26].

The lack of damage and exposure of the artery wall in the shunt model could potentially be regarded as source of bias. However, the aneurysm wall and site of rupture is significantly different than a healthy intracranial vessel wall. The ruptured aneurysm wall consists of a degenerated, almost decellularized, thin layer missing endothelial cells $[54,55]$. Acute arterial spasm seems not to play a decisive role in spontaneous haemostasis in intracranial bleeding [26]. Intracranial counter-pressure based on anatomical factors specific for each bleeding site and not premature coagulation in the tube system appear to be the main factor in cessation of blood flow $[27,26]$.

There are only a limited number of neurological scales for testing motor, sensory and reflex functions after SAH in rabbits $[56,16]$. Clinical assessment has also been performed using open-field locomotor activity and scoring of the rabbit's appetite $[57,20]$. Neurobehavioural testing of rabbits after SAH has not yet been described. Nevertheless, the relationship between neurological function (assessed in simple 4-6 scale scores) and severity of DCVS after SAH in rabbits is well established [56].

Single cisterna magna blood injection in rabbits demonstrates maximal vasoconstriction on day $2-4$ after SAH with vessel narrowing ranging from 19 to $55 \%$ when compared to baseline vessel diameter [16]. Additional blood injection postpones peak onset until day 7 with debated enhancement of DCVS (15-20\% [22], $23 \%[20])$. In direct comparison of single and double blood injection method, more severe morphometric (cross section area and artery wall thickness) vasospasm was documented in the double cisterna magna injection group [23]. In our experience, only mild 
Fig. 4 Pathophysiological parameters. a ICP increases to peak values close to diastolic blood pressure and returns to a steady state significantly higher than baseline values. b The increase in ICP causes a significant increase in MABP. c During the acute phase of the bleeding, CPP decreases but demonstrates a fast recovery, thanks to the compensatory increase in MABP. d At the time of SAH, marked reduction in CBF occurs in both hemispheres and recovers to $70 \%$ of baseline values within $20 \mathrm{~min}$. e Screenshot of typical waves of heart rate (HR), arterial blood pressure $(\mathrm{ABP})$, intracranial pressure (ICP), cerebral blood flow left $(\mathrm{CBF} 1)$ and right (CBF2) hemispheres after induction of SAH (dashed line)
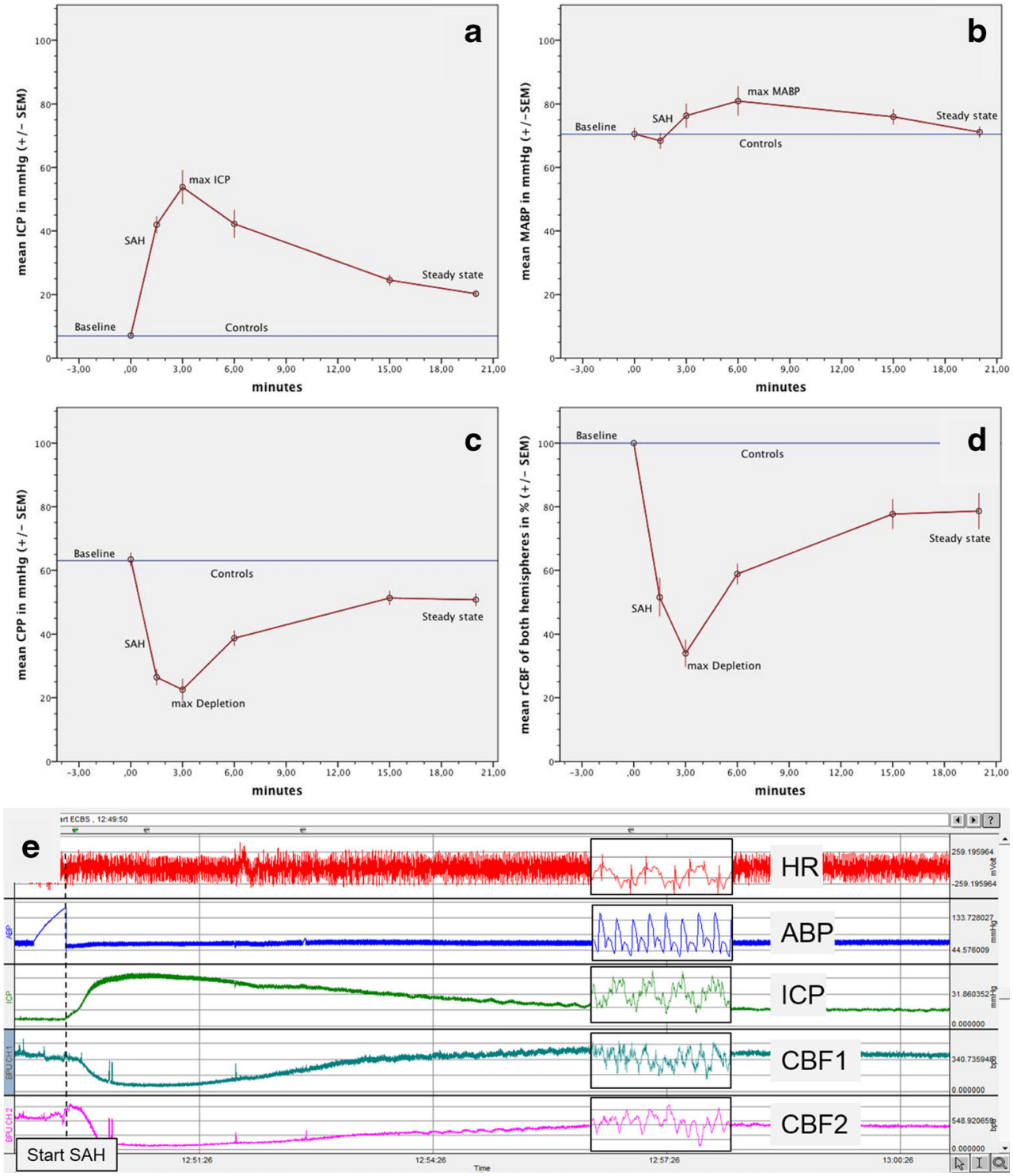

degrees of DCVS were achieved (20\% [58], $14 \%$ [59], $12 \%$ [59], $16 \%$ [60]) using the single injection cisterna magna model.

Egemen et al. reported the highest degree $(68 \%)$ reduction of angiographic diameter after acute experimental SAH in rabbits using a transclival craniotomy and basilar artery puncture approach. Initial results of the shunt-induced SAH technique revealed $53 \%$ DCVS. A possible explanation for the higher degree of DCVS in acute SAH models (vessel puncture and shunt-induced models) as compared to blood injection models might be early damage to endothelial cells [61, 62] which may aggravate DCVS. Vessel damage along with brain injury by means of neurodegeneration and apoptosis in the hippocampus CA1 and CA3 as well as basal cortex regions has been demonstrated $24 \mathrm{~h}$ after shunt-induced SAH in rabbits.
One specific advantage of the rabbit SAH model is that DSA can be readily applied to determine the degree of cerebral artery reduction over time. Basilar angiograms are performed either nonselectively using retrograde contrast agent injection through the cannulated subclavian artery (standard procedure) or by selective vertebral artery catheterization via the femoral artery [47]. DSA is still considered the gold standard for evaluating DCVS. Although DSA does not achieve similar spatial resolution as compared to morphometric determination of vessel diameter, it allows assessment of the entire artery length at different time points in the same animal.

In order to perform histological evaluation, arteries must be removed from their natural environment; chronological observation is not possible, and inequality of sections at different segments is a source of bias. In addition, formaldehyde fixation can result in basilar 


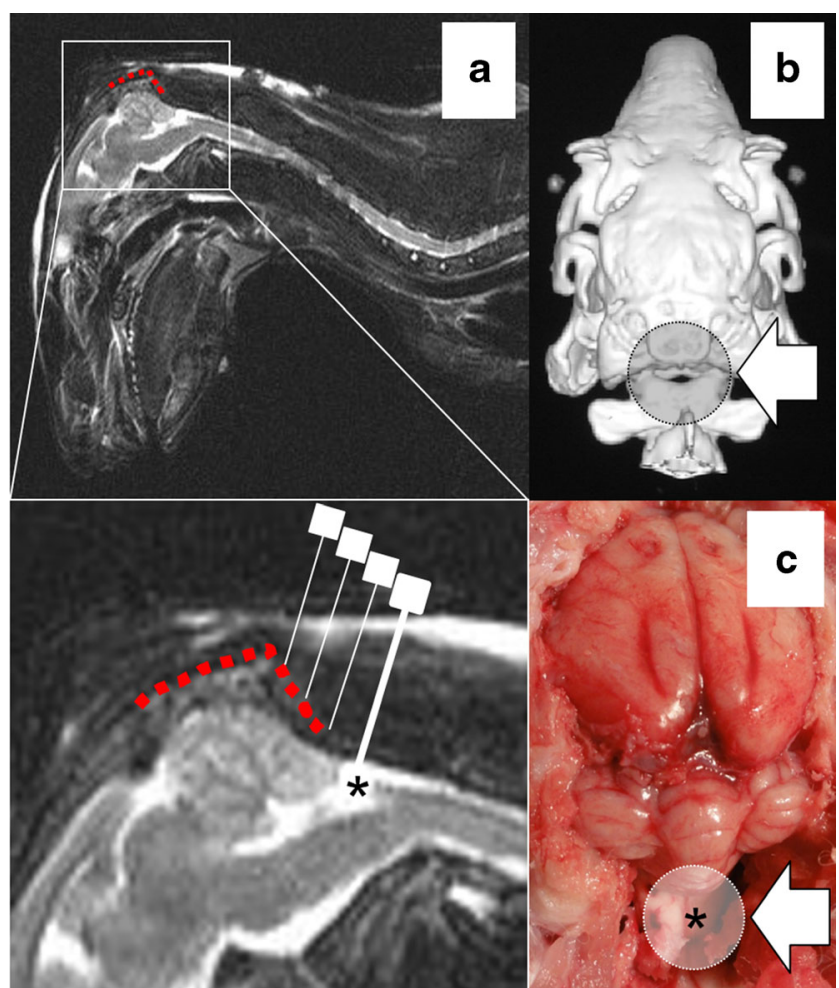

Fig. 5 Cisterna magna puncture. a The rabbit is placed in prone position with the head fixed in a head holder. The external occipital protuberance (red dashed line) is readily located through direct palpation. The needle is then moved caudally in the midline orthogonally to the bony external occipital protuberance until a gap $(*=$ cisterna magna) is detected. b The needle is then carefully and slowly pushed into the gap between the occipital bone and the atlas (dashed black circle). c Penetration of the atlanto-occipital membrane can be felt as loss of resistance and the tip of the needle reaching the middle of the cisterna magna $(*$, dashed white circle) artery calibre changes to such a degree that morphometric assessment of formaldehyde-fixed basilar arteries becomes unreliable [63].

Although real basilar artery diameter is most likely overestimated on CTA (control BA diameter male New Zealand white rabbits weighing 2.2-2.7 kg, 1,240 $\mu \mathrm{m}$ [64]; male Japanese white rabbits weighing $2.3-2.6 \mathrm{~kg}, \sim 1,100 \mu \mathrm{m}$ [65]; male New Zealand white rabbits weighing $2.5-3.5 \mathrm{~kg}$, $\sim 800 \mu \mathrm{m}$ [66]; male albino rabbits, $\sim 1,400 \mu \mathrm{m}$ [67]), relative reduction can be assessed noninvasively at various time points. An alternative method to noninvasive assessment of DCVS is transcranial Doppler sonography measurement of mean blood flow velocity and transoccipital peak systolic velocity $[65,68]$.

The most important advantages and limitations of the rabbit shunt-induced $\mathrm{SAH}$ model are summarised in Table 3 .

\section{Conclusions}

Awareness of technical details, physiological characteristics and appropriate monitoring methods guarantees successful implementation of the rabbit blood shunt model and allows the study of both EBI and DCVS after SAH. Improvement and refinement of clinical outcome measures, introduction of a saline control procedure and determination of the exact DCVS time course will further advance the model and help elucidate complex SAH sequelae and the screening of potential treatment modalities.

Table 3 Advantages and limitations of blood shunt SAH model in rabbits

\begin{tabular}{|c|c|}
\hline Advantages & Limitations \\
\hline $\begin{array}{l}\text { Relatively low costs, nonaggressive behaviour, } \\
\text { easy handling of animal }\end{array}$ & $\begin{array}{l}\text { Group-housing of male rabbits might not be possible } \\
\text { (fighting to establish hierarchy) }\end{array}$ \\
\hline $\begin{array}{l}\text { Mimics acute pathophysiology of aneurysm rupture } \\
\text { with brisk increase in ICP and global ischemia } \\
\text { (equal-sided bi-hemispheric CBF depletion) }\end{array}$ & $\begin{array}{l}\text { Limited availability of specific molecular biological } \\
\text { reagents and transgenic animal models as compared to } \\
\text { other species such as rat and mice }\end{array}$ \\
\hline $\begin{array}{l}\text { The bleeding is pulsatile and examiner-independent } \\
\text { (driven by the pressure gradient between MAP and ICP) }\end{array}$ & $\begin{array}{l}\text { Relatively high mortality rate of } 20-25 \% \text { due to respiratory } \\
\text { arrest and severe bradycardia during peak ICP }\end{array}$ \\
\hline $\begin{array}{l}\text { Provokes physiological reactions such as Cushing } \\
\text { phenomenon and decrease in heart and respiratory rate }\end{array}$ & $\begin{array}{l}\text { Limited neurological scales for testing motor, sensory and } \\
\text { reflex functions. Neurobehavioral tests not yet established }\end{array}$ \\
\hline $\begin{array}{l}\text { Provokes EBI ( } 24 \mathrm{~h} \text { ) by means of brain (hippocampus } \\
\text { and basal cortex) and vessel damage after acute SAH }\end{array}$ & $\begin{array}{l}\text { The exact time course of DCVS after blood shunt-induced } \\
\text { SAH must still be established }\end{array}$ \\
\hline Results in characteristic blood distribution with severe grades of SAH & $\begin{array}{l}\text { Pressurised reservoir would be needed to establish a saline } \\
\text { control group }\end{array}$ \\
\hline
\end{tabular}

Results in moderate to severe DCVS (72 h) after acute SAH

The model allows control over the severity of SAH by means of ICP increase and/or blood volume

Readily applied DCVS monitoring techniques such as DSA and CTA

Please see text for explanation of abbreviations 
Acknowledgments The authors thank Erica Holt, Editorial Office, Department of Neurosurgery, Aarau, Switzerland, for proofreading and editing the final manuscript. We appreciate the skillful management of animal care, anaesthesia and operative assistance from Daniel Mettler, DVM; Max Müller, DVM; and Daniel Zalokar and Olgica Beslac, Experimental Surgical Institute, Department of Clinical Research, University of Bern, Bern, Switzerland. We thank Michael Lensch, Head Research Nurse, Department of Intensive Care Medicine, Bern University Hospital and University of Bern, Bern, Switzerland, for real-time data monitoring and post-processing of the physiological parameters.

Sources of Funding This work was supported by the Department of Intensive Care Medicine, Bern University Hospital and University of Bern, Bern, Switzerland; the Department of Clinical Research, University of Bern, Bern, Switzerland and the Research Fund from the Kantonsspital Aarau, Aarau, Switzerland. We thank Informa Healthcare, for re-print permission for Fig. 1.

Compliance with Ethics Requirements The study was performed in accordance with the National Institutes of Health guidelines for the care and use of experimental animals and with the approval of the Animal Care Committee of the Canton of Bern, Switzerland. All surgical procedures were performed under sterile conditions at the Experimental Surgical Institute of the Department of Clinical Research at Bern University Hospital in Bern, Switzerland. A veterinary anaesthesiologist monitored the animals during surgery and throughout recovery.

Conflict of Interest None. The authors have no financial or commercial interest in any of the drugs, materials or equipment used. The authors are solely responsible for the design and conduct of the presented study.

\section{References}

1. Nieuwkamp DJ, Setz LE, Algra A, Linn FH, de Rooij NK, Rinkel GJ. Changes in case fatality of aneurysmal subarachnoid haemorrhage over time, according to age, sex, and region: a meta-analysis. Lancet Neurol. 2009;8(7):635-42. doi:10.1016/S1474-4422(09) 70126-7.

2. Malmivaara K, Juvela S, Hernesniemi J, Lappalainen J, Siironen J. Health-related quality of life and cost-effectiveness of treatment in subarachnoid haemorrhage. Eur J Neurol Off J Eur Fed Neurol Soc. 2012;19(11):1455-61. doi:10.1111/j.1468-1331.2012.03744.x.

3. Johnston SC, Selvin S, Gress DR. The burden, trends, and demographics of mortality from subarachnoid hemorrhage. Neurology. 1998;50(5):1413-8.

4. Ecker A, Riemenschneider PA. Arteriographic demonstration of spasm of the intracranial arteries, with special reference to saccular arterial aneurysms. J Neurosurg. 1951;8(6):660-7. doi:10.3171/jns. 1951.8.6.0660.

5. Roux S, Breu V, Giller T, Neidhart W, Ramuz H, Coassolo P, et al. Ro 61-1790, a new hydrosoluble endothelin antagonist: general pharmacology and effects on experimental cerebral vasospasm. J Pharmacol Exp Ther. 1997;283(3):1110-8.

6. Wanebo JE, Louis HG, Arthur AS, Zhou J, Kassell NF, Lee KS et al. Attenuation of cerebral vasospasm by systemic administration of an endothelin-A receptor antagonist, TBC 11251, in a rabbit model of subarachnoid hemorrhage. Neurosurgical focus. 1997;3(4): ARTICLE.

7. Vajkoczy P, Meyer B, Weidauer S, Raabe A, Thome C, Ringel F, et al. Clazosentan (AXV-034343), a selective endothelin A receptor antagonist, in the prevention of cerebral vasospasm following severe aneurysmal subarachnoid hemorrhage: results of a randomized, double-blind, placebo-controlled, multicenter phase IIa study. J Neurosurg. 2005;103(1):9-17. doi:10.3171/jns.2005.103.1.0009.

8. Macdonald RL, Kassell NF, Mayer S, Ruefenacht D, Schmiedek P, Weidauer S, et al. Clazosentan to overcome neurological ischemia and infarction occurring after subarachnoid hemorrhage (CONSCIOUS-1): randomized, double-blind, placebo-controlled phase 2 dose-finding trial. Stroke J Cereb Circ. 2008;39(11):301521. doi:10.1161/STROKEAHA.108.519942.

9. Macdonald RL, Higashida RT, Keller E, Mayer SA, Molyneux A, Raabe A, et al. Clazosentan, an endothelin receptor antagonist, in patients with aneurysmal subarachnoid haemorrhage undergoing surgical clipping: a randomised, double-blind, placebo-controlled phase 3 trial (CONSCIOUS-2). Lancet Neurol. 2011;10(7):618-25. doi:10. 1016/S1474-4422(11)70108-9.

10. Bederson JB, Levy AL, Ding WH, Kahn R, DiPerna CA, Jenkins 3rd $\mathrm{AL}$, et al. Acute vasoconstriction after subarachnoid hemorrhage. Neurosurgery. 1998;42(2):352-60. discussion 60-2.

11. Claassen J, Carhuapoma JR, Kreiter KT, Du EY, Connolly ES, Mayer SA. Global cerebral edema after subarachnoid hemorrhage: frequency, predictors, and impact on outcome. Stroke J Cereb Circ. 2002;33(5):1225-32.

12. Siironen J, Porras M, Varis J, Poussa K, Hernesniemi J, Juvela S. Early ischemic lesion on computed tomography: predictor of poor outcome among survivors of aneurysmal subarachnoid hemorrhage. J Neurosurg. 2007;107(6):1074-9. doi:10.3171/JNS-07/12/1074.

13. Pluta RM, Hansen-Schwartz J, Dreier J, Vajkoczy P, Macdonald RL, Nishizawa $\mathrm{S}$, et al. Cerebral vasospasm following subarachnoid hemorrhage: time for a new world of thought. Neurol Res. 2009;31(2):151-8. doi:10.1179/174313209X393564.

14. Sehba FA, Pluta RM, Zhang JH. Metamorphosis of subarachnoid hemorrhage research: from delayed vasospasm to early brain injury. Mol Neurobiol. 2011;43(1):27-40. doi:10.1007/s12035-010-8155-z.

15. Cahill J, Zhang JH. Subarachnoid hemorrhage: is it time for a new direction? Stroke J Cereb Circ. 2009;40(3 Suppl):S86-7. doi:10. 1161/STROKEAHA.108.533315.

16. Marbacher S, Fandino J, Kitchen ND. Standard intracranial in vivo animal models of delayed cerebral vasospasm. Br J Neurosurg. 2010;24(4):415-34. doi:10.3109/02688691003746274.

17. Edvinsson L, Egund N, Owman C, Sahlin C, Svendgaard NA. Reduced noradrenaline uptake and retention in cerebrovascular nerves associated with angiographically visible vasoconstriction following experimental subarachnoid hemorrhage in rabbits. Brain Res Bull. 1982;9(1-6):799-805.

18. Liszczak TM, Black PM, Tzouras A, Foley L, Zervas NT. Morphological changes of the basilar artery, ventricles, and choroid plexus after experimental SAH. J Neurosurg. 1984;61(3):486-93. doi:10.3171/jns.1984.61.3.0486

19. Chan RC, Durity FA, Thompson GB, Nugent RA, Kendall M. The role of the prostacyclin-thromboxane system in cerebral vasospasm following induced subarachnoid hemorrhage in the rabbit. J Neurosurg. 1984;61(6):1120-8. doi:10.3171/jns.1984.61.6.1120.

20. Endo S, Branson PJ, Alksne JF. Experimental model of symptomatic vasospasm in rabbits. Stroke J Cereb Circ. 1988;19(11):1420-5.

21. Baker KF, Zervas NT, Pile-Spellman J, Vacanti FX, Miller D. Angiographic evidence of basilar artery constriction in the rabbit: a new model of vasospasm. Surg Neurol. 1987;27(2):107-12.

22. Spallone A, Pastore FS. Cerebral vasospasm in a double-injection model in rabbit. Surg Neurol. 1989;32(6):408-17.

23. Zhou ML, Shi JX, Zhu JQ, Hang CH, Mao L, Chen KF, et al. Comparison between one- and two-hemorrhage models of cerebral vasospasm in rabbits. J Neurosci Methods. 2007;159(2):318-24. doi: 10.1016/j.jneumeth.2006.07.026.

24. Logothetis J, Karacostas D, Karoutas G, Artemis N, Mansouri A, Milonas I. A new model of subarachnoid hemorrhage in experimental animals with the purpose to examine cerebral vasospasm. Exp Neurol. 1983;81(2):257-78. 
25. Egemen N, Sanlidilek U, Zorlutuna A, Baskaya M, Bilgic S, Caglar $\mathrm{S}$, et al. Transclival approach to rabbit basilar artery for experimental induction of chronic vasospasm. Acta Neurochir. 1992;115(3-4): $123-6$.

26. Steiner L, Lofgren J, Zwetnow NN. Characteristics and limits of tolerance in repeated subarachnoid hemorrhage in dogs. Acta Neurol Scand. 1975;52(4):241-67.

27. McCormick PW, McCormick J, Zabramski JM, Spetzler RF. Hemodynamics of subarachnoid hemorrhage arrest. J Neurosurg. 1994;80(4):710-5. doi:10.3171/jns.1994.80.4.0710.

28. Trojanowski T. Experimental subarachnoid haemorrhage. Part I: a new approach to subarachnoid blood injection in cats. Acta Neurochir. 1982;62(3-4):171-5.

29. Offerhaus L, van Gool J. Electrocardiographic changes and tissue catecholamines in experimental subarachnoid haemorrhage. Cardiovasc Res. 1969;3(4):433-40.

30. Zhao W, Ujiie H, Tamano Y, Akimoto K, Hori T, Takakura K. Sudden death in a rat subarachnoid hemorrhage model. Neurol Med Chir. 1999;39(11):735-41. discussion 41-3.

31. Marbacher S, Sherif C, Neuschmelting V, Schlappi JA, Takala J, Jakob SM, et al. Extra-intracranial blood shunt mimicking aneurysm rupture: intracranial-pressure-controlled rabbit subarachnoid hemorrhage model. J Neurosci Methods. 2010;191(2):227-33. doi:10. 1016/j.jneumeth.2010.07.004

32. Marbacher S, Andereggen L, Neuschmelting V, Widmer HR, von Gunten M, Takala J, et al. A new rabbit model for the study of early brain injury after subarachnoid hemorrhage. J Neurosci Methods. 2012;208(2):138-45. doi:10.1016/j.jneumeth.2012.05.010.

33. Lin CL, Dumont AS, Su YF, Dai ZK, Cheng JT, Tsai YJ, et al. Attenuation of subarachnoid hemorrhage-induced apoptotic cell death with 17 beta-estradiol. Laboratory investigation. J Neurosurg. 2009;111(5):1014-22. doi:10.3171/2009.3.JNS081660.

34. Ondruska L, Rafay J, Okab AB, Ayoub MA, Al-Haidary AA, Samara $\mathrm{EM}$, et al. Influence of elevated ambient temperature upon some physiological measurements of New Zealand white rabbits. Vet Med. 2011;56(4):180-6.

35. Nakajima M, Date I, Takahashi K, Ninomiya Y, Asari S, Ohmoto T. Effects of aging on cerebral vasospasm after subarachnoid hemorrhage in rabbits. Stroke J Cereb Circ. 2001;32(3):620-8.

36. Hockel K, Trabold R, Scholler K, Torok E, Plesnila N. Impact of anesthesia on pathophysiology and mortality following subarachnoid hemorrhage in rats. Exp Transl Stroke Med. 2012;4(1):5. doi:10. 1186/2040-7378-4-5.

37. Barzago MM, Bortolotti A, Omarini D, Aramayona JJ, Bonati M. Monitoring of blood gas parameters and acid-base balance of pregnant and non-pregnant rabbits (Oryctolagus cuniculus) in routine experimental conditions. Lab Anim. 1992;26(2):73-9.

38. Schroeder CA, Smith LJ. Respiratory rates and arterial blood-gas tensions in healthy rabbits given buprenorphine, butorphanol, midazolam, or their combinations. J Am Assoc Lab Anim Sci. 2011;50(2):205-11.

39. Harper AM. Autoregulation of cerebral blood flow: influence of the arterial blood pressure on the blood flow through the cerebral cortex. J Neurol Neurosurg Psychiatry. 1966;29(5):398-403.

40. Markwalder TM, Grolimund P, Seiler RW, Roth F, Aaslid R. Dependency of blood flow velocity in the middle cerebral artery on end-tidal carbon dioxide partial pressure - a transcranial ultrasound Doppler study. J Cereb Blood Flow Metab Off J Int Soc Cereb Blood Flow Metab. 1984;4(3):368-72. doi:10.1038/jcbfm.1984.54.

41. Hayakawa T, Waltz AG. Experimental subarachnoid hemorrhage from a middle cerebral artery. Neurologic deficits, intracranial pressures, blood pressures, and pulse rates. Stroke J Cereb Circ. 1977;8(4):421-6.

42. Andereggen L, Neuschmelting V, von Gunten M, Widmer HR, Takala J, Jakob S, et al. The rabbit blood-shunt model for the study of acute and late sequelae of subarachnoid hemorrhage: technical aspects. J Vis Exp. 2014.

43. Marbacher S, Milavec H, Neuschmelting V, Andereggen L, Erhardt $\mathrm{S}$, Fandino J. Outer skull landmark-based coordinates for measurement of cerebral blood flow and intracranial pressure in rabbits. $\mathrm{J}$ Neurosci Methods. 2011;201(2):322-6. doi:10.1016/j.jneumeth. 2011.08.009.

44. Levinger IM. Special features of the rabbit cerebroventricular system, studied by the casting method. J Anat. 1971;109(Pt 3):527-33.

45. Andereggen L, Neuschmelting V, Von Gunten M, Widmer HR, Fandino J, Marbacher S. The role of microclot formation in an acute subarachnoid hemorrhage model in the rabbit. BioMed Research International. 2014.

46. Sugawara T, Ayer R, Jadhav V, Zhang JH. A new grading system evaluating bleeding scale in filament perforation subarachnoid hemorrhage rat model. J Neurosci Methods. 2008;167(2):327-34. doi:10. 1016/j.jneumeth.2007.08.004.

47. Marbacher S, Fathi AR, Muroi C, Coluccia D, Andereggen L, Neuschmelting V, et al. The rabbit blood shunt subarachnoid hemorrhage model. Acta neurochirurgica Supplement. 2014.

48. Bederson JB, Germano IM, Guarino L. Cortical blood flow and cerebral perfusion pressure in a new noncraniotomy model of subarachnoid hemorrhage in the rat. Stroke J Cereb Circ. 1995;26(6): 1086-91. Discussion 91-2.

49. Kamii H, Kato I, Kinouchi H, Chan PH, Epstein CJ, Akabane A, et al. Amelioration of vasospasm after subarachnoid hemorrhage in transgenic mice overexpressing CuZn-superoxide dismutase. Stroke J Cereb Circ. 1999;30(4):867-71. discussion 72.

50. Brawley BW, Strandness Jr DE, Kelly WA. The biphasic response of cerebral vasospasm in experimental subarachnoid hemorrhage. J Neurosurg. 1968;28(1):1-8. doi:10.3171/jns.1968.28.1.0001.

51. Nagai H, Suzuki Y, Sugiura M, Noda S, Mabe H. Experimental cerebral vasospasm. 1: factors contributing to early spasm. J Neurosurg. 1974;41(3):285-92.

52. Weir B, Erasmo R, Miller J, McIntyre J, Secord D, Mielke B. Vasospasm in response to repeated subarachnoid hemorrhages in the monkey. J Neurosurg. 1970;33(4):395-406. doi:10.3171/jns. 1970.33.4.0395.

53. Jakubowski J, Bell BA, Symon L, Zawirski MB, Francis DM. A primate model of subarachnoid hemorrhage: change in regional cerebral blood flow, autoregulation carbon dioxide reactivity, and central conduction time. Stroke J Cereb Circ. 1982;13(5):601-11.

54. Frosen J, Piippo A, Paetau A, Kangasniemi M, Niemela M, Hernesniemi J, et al. Remodeling of saccular cerebral artery aneurysm wall is associated with rupture: histological analysis of 24 unruptured and 42 ruptured cases. Stroke J Cereb Circ. 2004;35(10):2287-93. doi:10.1161/01.STR.0000140636.30204.da.

55. Kataoka K, Taneda M, Asai T, Kinoshita A, Ito M, Kuroda R. Structural fragility and inflammatory response of ruptured cerebral aneurysms. A comparative study between ruptured and unruptured cerebral aneurysms. Stroke J Cereb Circ. 1999;30(7):1396-401.

56. Jeon H, Ai J, Sabri M, Tariq A, Shang X, Chen G, et al. Neurological and neurobehavioral assessment of experimental subarachnoid hemorrhage. BMC Neurosci. 2009;10:103. doi:10.1186/1471-2202-10103.

57. Buemi M, Grasso G, Corica F, Calapai G, Salpietro FM, Casuscelli T, et al. In vivo evidence that erythropoietin has a neuroprotective effect during subarachnoid hemorrhage. Eur J Pharmacol. 2000;392(1-2): 31-4.

58. Marbacher S, Neuschmelting V, Graupner T, Jakob SM, Fandino J. Prevention of delayed cerebral vasospasm by continuous intrathecal infusion of glyceroltrinitrate and nimodipine in the rabbit model in vivo. Intensive Care Med. 2008;34(5):932-8. doi:10.1007/ s00134-008-0995-x.

59. Neuschmelting V, Fathi AR, Hidalgo Staub ET, Marbacher S, Schroth G, Takala J, et al. Norepinephrine-induced hypertension 
dilates vasospastic basilar artery after subarachnoid haemorrhage in rabbits. Acta Neurochir. 2009;151(5):487-93. doi:10.1007/s00701009-0287-4.

60. Fathi AR, Marbacher S, Graupner T, Wehrli F, Jakob SM, Schroth G, et al. Continuous intrathecal glyceryl trinitrate prevents delayed cerebral vasospasm in the single-SAH rabbit model in vivo. Acta Neurochir. 2011;153(8):1669-75. doi:10.1007/s00701-011-1049-7. discussion 75 .

61. Chen G, Wu J, Sun C, Qi M, Hang C, Gong Y, et al. Potential role of JAK2 in cerebral vasospasm after experimental subarachnoid hemorrhage. Brain Res. 2008;1214:136-44. doi:10.1016/j.brainres.2008. 03.085 .

62. Zubkov AY, Aoki K, Parent AD, Zhang JH. Preliminary study of the effects of caspase inhibitors on vasospasm in dog penetrating arteries. Life Sci. 2002;70(25):3007-18.

63. Hart MN, O'Donnell SL. Effects of formaldehyde fixation on basilar artery caliber. Stroke J Cereb Circ. 1980;11(1):99-100.

64. Zheng B, Zheng T, Wang L, Chen X, Shi C, Zhao S. Aminoguanidine inhibition of iNOS activity ameliorates cerebral vasospasm after subarachnoid hemorrhage in rabbits via restoration of dysfunctional endothelial cells. J Neurol Sci. 2010;295(1-2):97-103. doi:10.1016/ j.jns.2010.04.012.

65. Shao Z, Li J, Zhao Z, Gao C, Sun Z, Liu X. Effects of tetramethylpyrazine on nitric oxide/cGMP signaling after cerebral vasospasm in rabbits. Brain Res. 2010;1361:67-75. doi:10.1016/j. brainres.2010.09.011.

66. Laslo AM, Eastwood JD, Pakkiri P, Chen F, Lee TY. CT perfusionderived mean transit time predicts early mortality and delayed vasospasm after experimental subarachnoid hemorrhage. AJNR Am J Neuroradiol. 2008;29(1):79-85. doi:10.3174/ajnr.A0747.

67. Sasani M, Yazgan B, Celebi I, Aytan N, Catalgol B, Oktenoglu T, et al. Hypercholesterolemia increases vasospasm resulting from basilar artery subarachnoid hemorrhage in rabbits which is attenuated by vitamin E. Surg Neurol Int. 2011;2:29. doi:10.4103/2152-7806. 77600 .

68. Goksel HM, Ozum U, Oztoprak I. The therapeutic effect of continuous intracisternal L-Arginine infusion on experimental cerebral vasospasm. Acta Neurochir. 2001;143(3):277-85. 